\title{
Rapid selection and identification of Miscanthus genotypes with enhanced glucan and xylan yields from hydrothermal pretreatment followed by enzymatic hydrolysis
}

\author{
Taiying Zhang ${ }^{1}$, Charles E Wyman ${ }^{1,2}$, Katrin Jakob ${ }^{3}$ and Bin Yang ${ }^{1,4^{*}}$
}

\begin{abstract}
Background: Because many Miscanthus genotypes can be cultivated with relatively high productivity and carbohydrate content, Miscanthus has great potential as an energy crop that can support large scale biological production of biofuels.

Results: In this study, batch hydrothermal pretreatment at $180^{\circ} \mathrm{C}$ for 35 min followed by enzymatic hydrolysis was shown to give the highest total sugar yields for Miscanthus $x$ giganteus $\mathrm{CV}$. Illinois planted in Illinois. High throughput pretreatment at $180^{\circ} \mathrm{C}$ for $35 \mathrm{~min}$ and $17.5 \mathrm{~min}$ followed by co-hydrolysis in a multi-well batch reactor identified two varieties out of 80 that had significantly higher sugar yields from pretreatment and enzymatic hydrolysis than others. The differences in performance were then related to compositions of the 80 varieties to provide insights into desirable traits for Miscanthus that enhance sugar yields.

Conclusions: High throughput pretreatment and co-hydrolysis (HTPH) rapidly identified promising genotypes from a wide range of Miscanthus genotypes, including hybrids of Miscanthus sacchariflorus/M. sinensis and Miscanthus lutarioriparius, differentiating the more commercially promising species from the rest. The total glucan plus xylan content in Miscanthus appeared to influence both mass and theoretical yields, while lignin and ash contents did not have a predictable influence on performance.
\end{abstract}

Keywords: Miscanthus, High throughput, Hydrothermal pretreatment, Co-hydrolysis

\section{Background}

World petroleum reserves are being depleted at an accelerating rate and production rates are slowing. In fact, Kerr reported that conventional oil production might have already reached its peak instead of plateauing between 2015 and 2020 as predicted earlier [1-3]. In addition, a move from fossil to renewable fuels is vital if we hope to slow the impacts of carbon dioxide accumulation on global climate. Against this background, production of fuels from cellulosic biomass is one

\footnotetext{
* Correspondence: binyang@tricity.wsu.edu

${ }^{1}$ Center for Environmental Research and Technology, Bourns College of Engineering, University of California, 1084 Columbia Avenue, Riverside, CA 92507, USA

${ }^{4}$ Center for Bioproducts and Bioenergy, Washington State University, 2710 University Drive, Richland, WA 99354, USA

Full list of author information is available at the end of the article
}

promising option for large-scale and low-cost sustainable production of liquid fuels with low greenhouse gas emissions. Crops planted for the specific purpose of energy production are expected to play an essential role in meeting the Energy Independence and Security Act of 2007 in the United States. In the recent report entitled "U. S. Billion Ton update: Biomass Supply for Bioenergy and Bioproducts Industry" jointly released by DOE and USDA, energy crops were predicted to become dominant at prices above $\$ 50$ per dry ton after 2022 with the baseline about $37 \%$ of total biomass at $\$ 60$ per dry total [4]. Among various potential perennial energy crops, Miscanthus, which is native to Asia and the Pacific Islands, has been selected and studied as one of the most promising energy crops for Europe over the past two decades [5-8]. Based on Miscanthus field trials at 
different locations in Europe, a growth model towards more robust yield predication on the basis of different climatic and soil condition was developed in Europe [9]. Since Miscanthus has been successfully produced with high yields over a wide range of climatic conditions in Europe, it also became of interest as a dedicated biomass crop in the US, and first field trials were planted in Illinois and Arkansas [10-14]. It has been reported that the average productivity of Miscanthus $\mathrm{x}$ giganteus was $30 \mathrm{t} /$ ha-year and the maximum productivity was as high as $61 \mathrm{t} / \mathrm{ha}$-year over a 3 year period in side-by-side trials while the productivity of switchgrass, one of the most studied energy crops in the United States, was reported to be $15.8 \mathrm{t} / \mathrm{ha}$-year in upland and $12.6 \mathrm{t} / \mathrm{ha}$-year in lowland varieties [10]. Thus, Miscanthus could potentially reduce the land requirements to support U.S. biofuels production $[11,12]$. Further study on the effects of management on Miscanthus x giganteus productivity in different environments based on four locations in the United States provided more insights on how to improve the productivity of Miscanthus x giganteus and its capacity as a stable and reliable biomass feedstock [13]. In addition to high productivity, Miscanthus could be very important for the relatively high carbohydrate content $(>60 \%)$ of some genotypes. The Miscanthus genus in general, and Miscanthus x giganteus in particular, have been identified as prime candidates for biomass energy crops because of an array of other attributes including high photosynthetic efficiency, strong stress tolerance, perennial growth, low nutrient requirements, and high carbon content $[5,14]$. For biological processing to ethanol and other products, it is particularly beneficial to identify genotypes that are most easily processed into sugars.

As with other types of lignocellulosic biomass, pretreatment is essential to disrupt the natural recalcitrance of Miscanthus to release fermentable sugars with high yields with the fungal enzymes typically used. However, as summarized in Table 1, only a few studies have been published to determine the performance of different pretreatment methods followed by enzymatic hydrolysis for conversion of Miscanthus into fermentable sugars, including mechanical size reduction with sodium chlorite delignification [15], ammonia fiber expansion (AFEX) [16], one step extrusion $/ \mathrm{NaOH}$ pretreatment [14], ethanol organosolv processing [17], dilute acid steam explosion [18], and treatment with alkaline peroxide combined with electrolyzed water [19]. Overall, sugar yields from cellulose and hemicellulose, as a percent of the maximum possible, were reported to vary from $61.3 \%$ [18] to $98 \%$ [17] and from $38 \%$ [14] to $100 \%$ [15], respectively.

Besides being affected by pretreatment methods, the fermentable sugar yields of Miscanthus were strongly influenced by the genotype, production site, climate, age, and plant part(s) harvested. Biomass quality was also impacted by such factors as cellulose and lignin biosynthesis and deposition and extractives [20,21]. New functional genomics and plant biotechnology tools could genetically optimize Miscanthus for liquid fuel production by identification of genes that improve breakdown to sugars through modification of growth rates, environmental stress tolerance, and cell wall composition, as being applied to switchgrass and alfalfa [22,23]. However, because the effect of changes in plant structure on sugar release cannot yet be predicted a' priori, pretreatment and enzymatic hydrolysis must currently be directly applied to evaluate how sugar release changes with genetic modifications in biomass so we can identify traits that are desirable for biofuels feedstocks.

Among pretreatment options, hydrothermal pretreatment with just hot water has produced reasonably high sugar yields with various biomass feedstocks, such as corn stover [24], wheat straw [25], switchgrass [26], and poplar [27]. Furthermore, hydrothermal pretreatment advantages include no requirement for chemical additions, simple operation, and low cost materials of construction that would be of great economic advantage if

Table 1 Summary of Miscanthus pretreatment data reported in the literature

\begin{tabular}{|c|c|c|c|c|}
\hline \multirow{2}{*}{\multicolumn{2}{|c|}{ Pretreatment }} & \multicolumn{2}{|c|}{ Overall conversion*, \% } & \multirow[t]{2}{*}{ Ref. } \\
\hline & & Glucan & Xylan & \\
\hline \multicolumn{2}{|l|}{ ball-milling: $\mathrm{NaCl} /$ glacial acetic acid, $70^{\circ} \mathrm{C}, 1 \mathrm{~h}$} & 100 & 90.6 & [15] \\
\hline \multicolumn{2}{|l|}{ ammonia fiber expansion: $60^{\circ} \mathrm{C}, 5 \mathrm{~min}$} & 96 & 81 & [16] \\
\hline \multicolumn{2}{|l|}{ one step extrusion/ $\mathrm{NaOH}$ : solid to liquid ratio of $1: 6, \mathrm{NaOH} 12 \%(\mathrm{w} / \mathrm{w})$ pretreatment at $70^{\circ} \mathrm{C}$ for $4 \mathrm{~h}$} & 69 & 38 & [14] \\
\hline \multicolumn{2}{|l|}{ ethanol organosolv process } & 98 & 73 & [17] \\
\hline \multirow{2}{*}{$\begin{array}{l}\text { diluted acid explosion: } 0.75 \% \mathrm{H}_{2} \mathrm{SO}_{4} \text { at } 100^{\circ} \mathrm{C} \text { for } 14 \mathrm{~h} \text {; atmospheric air } / \mathrm{H}_{2} \mathrm{O}_{2} \text { wet explosion with } \\
\text { solid loading } 15 \% \text { at } 170^{\circ} \mathrm{C} \text { under } 200 \text { bar for } 5 \mathrm{~min}\end{array}$} & air & 61.3 & 94.9 & [18] \\
\hline & $\mathrm{H}_{2} \mathrm{O}_{2}$ & 63.7 & 82.4 & \\
\hline \multicolumn{2}{|l|}{ alkaline peroxide: $\left(50^{\circ} \mathrm{C}, 24 \mathrm{~h}\right)$, electrolyzed water at $121^{\circ} \mathrm{C}$ for 50 min } & 84 & N/A & [19] \\
\hline
\end{tabular}

* Overall conversion refers to total conversion resulted from pretreatment and sequential enzymatic hydrolysis on the basis of original glucan or xylan content of raw Miscanthus. 
high total sugar yields could be realized. Thus, it is highly desirable to indentify Miscanthus plants that achieve high sugar yields from the coupled operations of hydrothermal pretreatment and enzymatic hydrolysis.

Conventional pretreatment and enzymatic hydrolysis methods are very labor intensive and time consuming, making it very expensive and/or slow to screen large numbers of plants to find those that display enhanced sugar yields. However, high throughput methods have been recently developed that allow rapid screening of large numbers of combinations of plants, pretreatment conditions, and enzyme loadings and formulations to narrow the field to those with high sugar release or other desirable features [28-34]. These methods can also handle much smaller amounts of samples than conventional approaches, thereby allowing characterization of sugar release from different anatomical fractions [30]. Such rapid screening methods have been applied to a sorghum diversity panel [32], a high-throughput microplate for enzymatic hydrolysis of lignocellulosic biomass [33], and high-throughput screening of cellulose following ionic liquid treatment [34]. Recent rapid screening studies of enzymatic hydrolysis using different glycosyl hydrolases were employed to compare AFEX and dilute acid pretreatment of corn stover [35,36]. Studer et al. developed a higher temperature, high throughput method appropriate for hydrothermal and other thermochemical pretreatments based on the 96 well-plate format and employing a custom made steam chamber for rapid heating and cool down of multiple reaction vessels [29]. Results for poplar without liquid-solid separation after pretreatment in the multi-well plate system were shown to be statistically identical to those from standard pretreatment and hydrolysis methods with liquid-solid separation and solid washing [29]. Advantage has also been taken of the ability to process small sample sizes to determine variations in sugar release among tree growth rings and to identify promising traits in poplar as well as the high throughput determination of glucan and xylan fractions in lignocelluloses developed by Selig et al. $[28,31,37]$.

In this study, the previously established HTPH system was applied to screen Miscanthus genotypes with the goal of identifying those that displayed enhanced release of glucan and xylan from the coupled operations of hydrothermal pretreatment and enzymatic hydrolysis. Conventional hydrothermal pretreatment in tubular batch reactors followed by enzymatic hydrolysis was applied first to identify baseline conditions that gave the highest total sugar yields from Miscanthusx giganteus $c v$. Illinois planted in Illinois. Then the HTPH system was applied to 80 different Miscanthus varieties to screen for those that gave the highest sugar release and identify the most promising genotypes based on baseline conditions determined from conventional pretreatment results. As reported in a companion paper (in preparation), a flowthrough reactor system was then applied to follow release of sugars and other biomass components and gain new insights into biomass deconstruction patterns that favour high sugar yields based on hydrothermal pretreatment.

\section{Results and discussion}

\section{Miscanthus compositions}

As the most widely cultivated biomass genotype currently available, Miscanthus $x$ giganteus cv. Illinois was selected as the reference material for identification of pretreatment conditions that gave the highest total glucose plus xylose release from conventional pretreatment and subsequent enzymatic hydrolysis in the batch tubes. This genotype contained $42.87 \pm 0.64 \%$ glucan, $22.02 \pm 0.32 \%$ xylan, $19.67 \pm 0.01 \%$ lignin, $2.33 \pm 0.10 \%$ ash, $3.21 \%$ water extractives, and $5.80 \%$ ethanol extractives. The average moisture content of Miscanthus $x$ giganteus cv. Illinois was determined to be $7.37 \pm 0.11 \%$ based on 10 tests. The data reported for the 80 Miscanthus genotypes (provided as the Additional file 1: Table S1 and Additional file 2: Table S2) include averages, minimum and maximum contents of glucan, xylan, the total glucan plus xylan as carbohydrates, and lignin. The average compositions of all 80 Miscanthus genotypes were $40.74 \%$ glucan, $21.01 \%$ xylan, $24.03 \%$ lignin, and $2.83 \%$ ash. However, the 80 Miscanthus genotypes showed significant diversity in compositions, with glucan levels ranging from $27.7 \%$ to $48.6 \%$, xylan from $19.6 \%$ to $27.1 \%$, lignin from $15.5 \%$ to $27.8 \%$, and ash from $1.10 \%$ to $7.37 \%$. Thus, these samples were expected to enable the study of how composition affects sugar release from pretreatment and hydrolysis and aid in the selection of desirable traits to target for improvements. The total glucan and xylan content, which was important to establish the maximum possible ethanol yield, ranged from $48.6 \%$ to $72.8 \%$. The genotypes with the highest total glucan and xylan content of $48.6 \%$ glucan and $24.2 \%$ xylan also had the highest glucan content and could realize a theoretical ethanol yield of 127 gallons from glucan and xylan per dry ton of feedstock, as calculated by the DOE Theoretical Ethanol Yield Calculator [38]. The theoretical ethanol yield of Miscanthus $x$ giganteus $c v$. Illinois was 113 gallons ethanol per dry ton feedstock. Therefore, Miscanthus has excellent potential for high ethanol yields.

\section{Batch pretreatment and enzymatic hydrolysis}

Figure 1 summarizes glucan and xylan sugar yields from batch hydrothermal pretreatment (Stage 1) of Miscanthus $x$ giganteus $c v$. Illinois in tube reactors at $180^{\circ} \mathrm{C}$, $200^{\circ} \mathrm{C}$, and $220^{\circ} \mathrm{C}$ and from subsequent enzymatic 


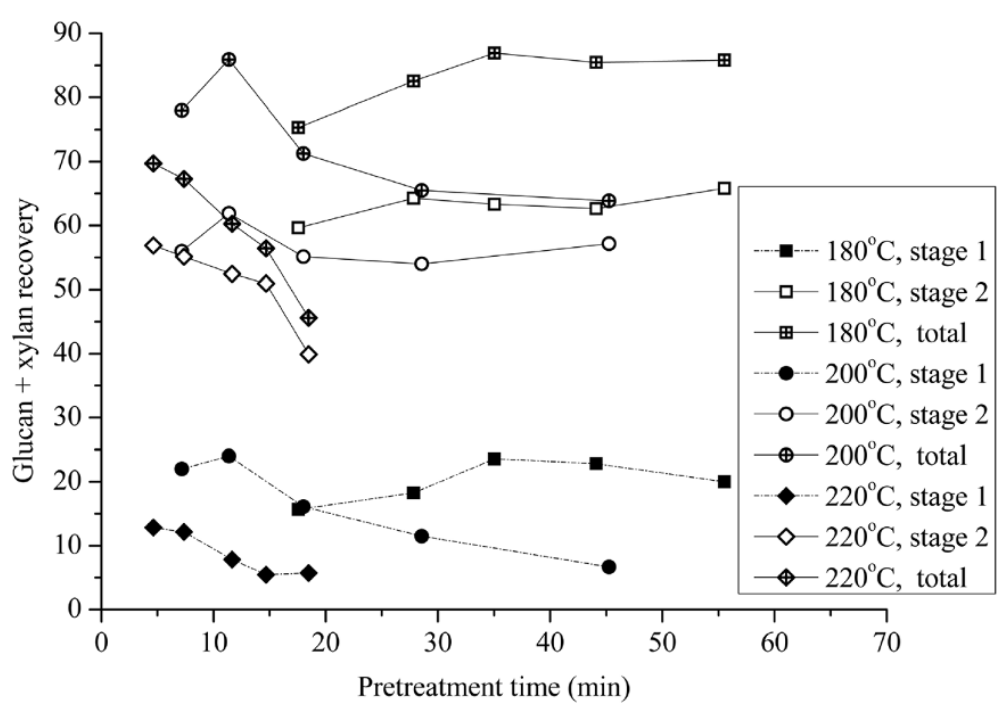

Figure 1 Glucan plus xylan yields vs. pretreatment time from hydrothermal pretreatment of Miscanthus $x$ giganteus cv. Illinois. Hydrothermal pretreatments at $180^{\circ} \mathrm{C}, 200^{\circ} \mathrm{C}$ and $220^{\circ} \mathrm{C}$ followed by enzymatic hydrolysis with $60 \mathrm{FPU} / \mathrm{g}$ (glucan + xylan) at $50^{\circ} \mathrm{C}$ for 72 hours.

hydrolysis of the washed solids (Stage 2) at the conditions noted. Soluble xylan and glucan yields in Stage 1 increased with pretreatment time at $180^{\circ} \mathrm{C}$ and $200^{\circ} \mathrm{C}$ to peak values after 35 and 11.4 minutes, respectively, before dropping with longer times due to xylose degradation becoming more rapid than xylan hydrolysis to xylose. However, the glucan plus xylan based sugar yields in Stages 1 and 2 combined dropped from 69.7\% to $45.6 \%$ as reaction time increased from $4.6 \mathrm{~min}$ to $18.5 \mathrm{~min}$ at $220^{\circ} \mathrm{C}$ because xylan degradation became very rapid and pronounced in Stage 1.

For Stage 2, glucan plus xylan yields reached peak values of 64.2 and $61.9 \%$ after 28 and 11.4 minutes for pretreatment at $180^{\circ} \mathrm{C}$ and $200^{\circ} \mathrm{C}$, respectively, but sugar yields continually dropped with increasing pretreatment times at $220^{\circ} \mathrm{C}$ for the range of times tested. Sugar yields from enzymatic hydrolysis of pretreated solids were relatively high, ranging from 73.5 to $93.1 \%$ over the range of pretreatment temperatures tested.

Total glucan plus xylan yields from pretreatment (Stage 1 ) at $180^{\circ} \mathrm{C}$ combined with enzymatic hydrolysis (Stage 2) increased from $79.5 \%$ to $86.9 \%$ as pretreatment time was increased from $17.5 \mathrm{~min}$ to $35 \mathrm{~min}$ and then dropped slowly with extended pretreatment time. At $200^{\circ} \mathrm{C}$, overall glucan plus xylan yields from Stage 1 plus Stage 2 increased from $78.0 \%$ to $85.9 \%$ as pretreatment time increased from $7.2 \mathrm{~min}$ to $11.4 \mathrm{~min}$ and then dropped. Increasing the temperature to $220^{\circ} \mathrm{C}$ resulted in a maximum overall glucan plus xylan yield of $69.7 \%$ from the two stages combined at the shortest sampling time of 4.6 min with a rapid drop after that, suggesting that the rapid degradation of xylose resulted in overall sugar loss at $220^{\circ} \mathrm{C}$. Thus, similar high total sugar yields of about $85 \%$ were obtained at $180^{\circ} \mathrm{C}$ and $200^{\circ} \mathrm{C}$ for Miscanthus $x$ giganteus $c v$. Illinois pretreatment followed by enzymatic hydrolysis, while sampling times were not short enough to capture high sugar yields at $220^{\circ} \mathrm{C}$. Because such short times would be impractical to implement commercially, additional experiments were not run to determine if yields would improve at shorter times. Thus, pretreatment times to achieve the highest overall glucan plus xylan yields from the two stages for Miscanthus $x$ giganteus $\mathrm{cv}$. Illinois were $35 \mathrm{~min}$ at $180^{\circ} \mathrm{C}$ and $11.4 \mathrm{~min}$ at $200^{\circ} \mathrm{C}$, corresponding to similar pretreatment severities $\left(\log \mathrm{R}_{0}\right)$ [39] of 3.9 and 4.0, respectively.

The maximum glucan plus xylan yields for hydrothermal pretreatment followed by enzymatic hydrolysis were very similar to those reported in the literature for AFEX and ethanol organosolv pretreatments of Miscanthus, as shown in Table 1. In addition, as a result of the higher carbohydrate content of Miscanthus compared to other biomass listed in Table 1, the overall mass sugar yield of $55.7 \mathrm{~g}$ glucan plus xylan per $100 \mathrm{~g}$ of dry Miscanthus $x$ giganteus $c v$. Illinois was greater than mass yields from application of hydrothermal pretreatment to other feedstocks listed in Table 2, such as 40.8 g glucan + xylan per $100 \mathrm{~g}$ dry corn stover [24] and $52.6 \mathrm{~g}$ glucan + xylan per $100 \mathrm{~g}$ dry wheat straw [26]. Although pretreatment temperatures and solids loadings were different for these five feedstocks, the log of the pretreatment severities at the highest overall glucan and xylan yields were in the range from about 3.9 to 4.0 for Miscanthus $x$ giganteus cv. Illinois, corn stover, and poplar. However, both corn stover and poplar studies used higher solids loadings and achieved higher xylan yields but lower glucan yields 
Table 2 Comparison of Miscanthus and other selected biomass feedstocks

\begin{tabular}{|c|c|c|c|c|c|c|c|c|}
\hline \multirow[t]{2}{*}{ Biomass } & \multicolumn{2}{|c|}{$\begin{array}{l}\text { Composition } \\
\text { (\% dry weight raw) }\end{array}$} & \multirow{2}{*}{$\begin{array}{l}\text { Theoretical EtOH } \\
\text { yield (gal/dry } \\
\text { ton feedstock)* }\end{array}$} & \multirow[t]{2}{*}{$\begin{array}{l}\text { Pretreatment } \\
\text { condition }\end{array}$} & \multirow[t]{2}{*}{$\begin{array}{l}\text { Enzymatic } \\
\text { hydrolysis }\end{array}$} & \multicolumn{3}{|c|}{ Sugar yield ** } \\
\hline & Glu & Xyl & & & & Glu & Xyl & Total \\
\hline $\begin{array}{l}\text { Miscanthus } x \text { giganteus } \\
\text { cv. Illinois in this study }\end{array}$ & 42.9 & 22.0 & 113 & $\begin{array}{l}180^{\circ} \mathrm{C}, 10 \% \text { solid loading, } \\
35 \mathrm{~min}, \log \mathrm{R}_{0} 3.90\end{array}$ & $\begin{array}{l}60 \text { FPU Spezyme CP plus } \\
120 \text { CBU Novozym } 188 \text { per } \\
\text { gram glucan + xylan, } 72 \mathrm{~h}\end{array}$ & 92 & 74 & 55.7 \\
\hline Corn stover [24] & 36.1 & 21.4 & 100.3 & $\begin{array}{l}210^{\circ} \mathrm{C}, 50 \% \text { solid loading, } \\
6 \mathrm{~min}, \log \mathrm{R}_{0} 4.02\end{array}$ & $\begin{array}{l}60 \text { FPU Spezyme CP plus } \\
120 \text { CBU Novozym } 188 \text { per } \\
\text { gram glucan + xylan, } 72 \mathrm{~h}\end{array}$ & 61.1 & 87.6 & 40.8 \\
\hline Wheat straw [25] & 37.8 & 22.8 & 105.6 & $\begin{array}{l}188^{\circ} \mathrm{C}, 10 \% \text { solid loading, } \\
40 \mathrm{~min}, \log \mathrm{R}_{0} 4.19\end{array}$ & $\begin{array}{l}15 \mathrm{FPU} \text { celluclast plus } 15 \mathrm{IU} \\
\text { Novozym } 188 \text { per gram } \\
\text { dry substrate, } 72 \mathrm{~h}\end{array}$ & 91 & 80 & 52.6 \\
\hline Switchgrass [26] & 32.2 & 20.3 & 91.5 & $\begin{array}{l}190^{\circ} \mathrm{C}, 5 \% \text { solid loading, } \\
10 \mathrm{~min}, \log _{0} 3.64\end{array}$ & $\begin{array}{l}15 \mathrm{FPU} \text { cellulase per } \\
\text { gram glucan, } 72 \mathrm{~h}\end{array}$ & N/A & 73.1 & N/A \\
\hline Hybrid Poplar [27] & 44 & 15 & 102.5 & $\begin{array}{l}200^{\circ} \mathrm{C}, 15 \% \text { solid loading, } \\
10 \mathrm{~min}, \log \mathrm{R}_{0} 3.94\end{array}$ & $\begin{array}{l}40 \text { FPU Spezyme CP plus } \\
40 \text { CBU Novozym } 188 \text { per } \\
\text { gram glucan, } 48 \mathrm{~h}\end{array}$ & 63.3 & 85.3 & 45.5 \\
\hline
\end{tabular}

Glu-glucan, xyl-xylan, lig-lignin.

*Theoretical EtOH yields were calculated by NREL Theoretical Ethanol Yield Calculator [38]

** Sugar yields for glu and xyl were \%, the totals of glu and xyl were g/100 dry weight.

$[24,40]$. This suggests that corn stover and poplar require more severe hydrothermal pretreatment to disrupt the cellulose structure enough to gain higher glucan yields in Stage 2. Wheat straw was reported to require more severe pretreatment $\left(\log R_{0}\right.$ of 4.15$)$ to achieve the highest overall glucan and xylan yield, while the highest glucan yield of 91\% (mainly in Stage 2) was obtained with relatively low enzyme loading of 15 FPU Celluclast plus 15 IU Novozym 188 per gram dry substrate (about 39.7 FPU cellulase per gram glucan) [25].

High throughput pretreatment and co-hydrolysis (HTPH) of Miscanthus

The HTPH system was applied to 80 Miscanthus genotypes with different characteristics to rapidly measure overall glucan and xylan yields from hydrothermal pretreatment at $180^{\circ} \mathrm{C}$ for $0,17.5$, and $35 \mathrm{~min}$ followed by enzymatic hydrolysis of the entire pretreated slurry $\left(180^{\circ}\right.$ $\mathrm{C}$ for $35 \mathrm{~min}$ is the optimal condition based on our previous batch tube experiments, data unpublished). A scatter matrix $\mathrm{S}(\mathrm{x})$ of compositions and HTPH sugar yields (mass yields, g/100 g raw Miscanthus) for the 80 Miscanthus genotypes is presented in Additional file 3: Figure S1 (selected data with $\mathrm{R}^{\wedge} 2>0.5$ are shown in Figure 2) $\mathrm{X}=\left(\begin{array}{lll}\mathrm{x}_{1} & x_{2} & \mathrm{x}_{10}\end{array}\right)$ ' to provide a statistical estimate of the covariance matrix of the multivariate normal distribution and allow determination of whether the variables are correlated and whether the correlation is positive or negative. The data in Figure 2 and Additional file 3: Figure S1 were normalized by the average

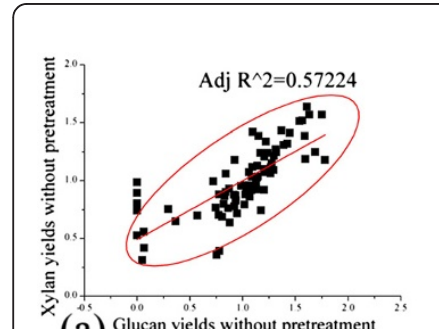

(a) Glucan yields without pretreatment

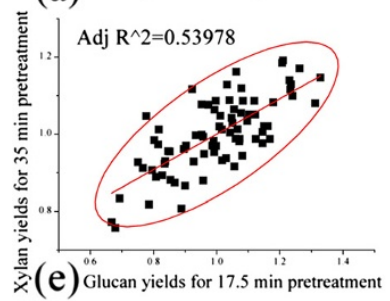

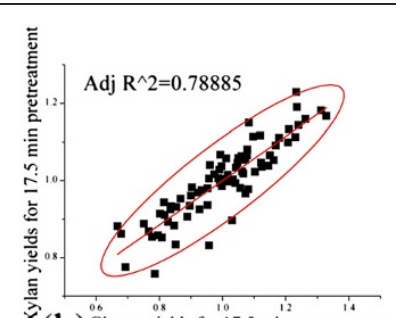

(b) ${ }_{\text {Glucan yields for } 17.5 \text { min pretreatment }}^{\text {of }}$

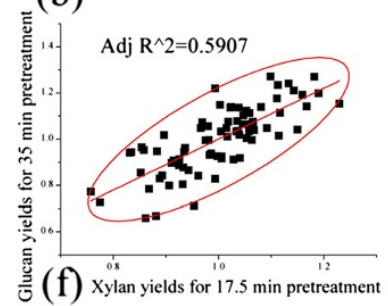

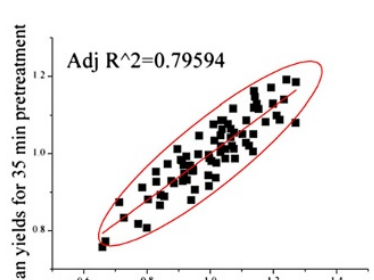

(c) Glucan yields for 35 min pretreatment

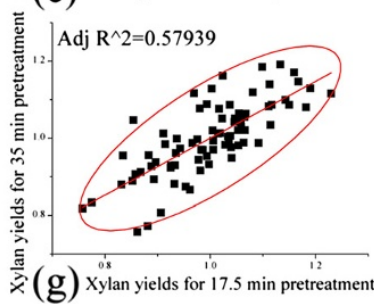

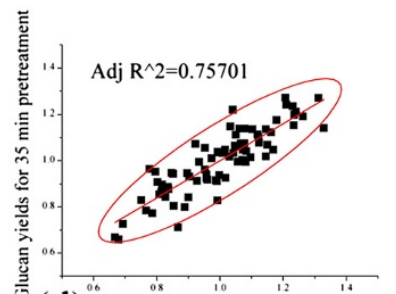

(d) Glucan yields for 17.5 min pretreatment

Figure $\mathbf{2}$ Normalized scatter matrix of $\mathbf{8 0}$ Miscanthus HTPH glucan and xylan mass yields. HTPH glucan and xylan mass yields ( $\mathrm{g} / 100 \mathrm{~g}$ dw raw Miscanthus) from hydrothermal pretreatment at $180^{\circ} \mathrm{C}$ in $0,17.5 \mathrm{~min}$, and $35 \mathrm{~min}$. 
values of 80 Miscanthus genotypes. The 10 components in the scatter matrix (4 compositional variables plus 6 sugar yields for three different pretreatment times followed by co-enzymatic hydrolysis) were assumed independent so that the regular covariance matrix would be a diagonal matrix. The diagonal in Additional file 3: Figure S1 was filled with the variables $\left(\mathrm{x}_{\mathrm{i}}\right)$ of the scatter matrix for each column, and the results and discussion focuses on the lower left part in Additional file 3: Figure S1. Additional file 3: Figure S1 included all the scatter plots with ellipse matrix $\left(\mathrm{x}_{\mathrm{i}}^{\prime}\right)$ and linear fit applied at the $95 \%$ confidence level with the adjusted R-square between any of ten variables in order to reveal correlations. For example, the first column $\left(\mathrm{x}_{1}\right)$ (K-lignin column) showed the scatter plots of other nine variables $\left(x_{i}, i=2-9\right)$ as listed in each row in the diagonal versus K-lignin content with ellipse matrix and linear fit with the adjusted R-square to investigate the correlations. No obvious correlation was found between sugar yields from enzymatic hydrolysis of raw Miscanthus and lignin contents, but a negative correlation was observed between sugar yields and lignin contents following hydrothermal pretreatment for 17.5 and $35 \mathrm{~min}$, consistent with recently reported findings for poplar [28].

In the second left column (glucan content column) in Additional file 3: Figure S1, a positive correlation was found between glucan and xylan contents (the third row) in raw Miscanthus, suggesting a structural correlation between them. A negative correlation was observed between glucan contents and sugar yields for enzymatic hydrolysis without pretreatment, suggesting cellulose in raw biomass was a strong contributor to recalcitrance $[15,19,25]$. However, overall mass sugar yields (g sugar/100 g biomass) following pretreatments at 17.5 and $35 \mathrm{~min}$ in the HTPH system were positively correlated to glucan content, which simply emphasized that high glucan content was one of the vital criteria for cellulosic feedstocks.

Correlations between xylan content and other compositions and sugar yields (the third left column (xylan content column) in Additional file 3: Figure S1) were similar to correlations found for glucan content, except that sugar yields from enzymatic hydrolysis of raw Miscanthus were less negatively correlated to xylan content, undoubtedly due to the lower recalcitrance of xylan than glucan.

Correlations between ash content and other compositions and sugar yields are shown in the fourth left column (ash content column) in Additional file 3: Figure S1. Although a negative correlation was found between K-lignin content and ash content in raw Miscanthus, glucan content and xylan content were not obviously related to ash content. This indicated that the small amount of ash did not appear to affect structural carbohydrates content. Sugar yields did not show any significant correlation to ash content for pretreatment times of $0,17.5$, and $35 \mathrm{~min}$ followed by enzymatic hydrolysis.

Besides the correlations of the composition variables and sugar yields, glucan and xylan yields for three different pretreatment times showed interesting and most significant correlations (Figure 2). The strongest positive correlations were found between HTPH glucan and xylan yields with $\mathrm{R}^{\wedge} 2$ values of $0.5772,0.7888$, and 0.7959 for the pretreatments at $0 \mathrm{~min}, 17.5 \mathrm{~min}$ and $35 \mathrm{~min}$, respectively (Figures 2a, 2b, and 2c). These results suggested a strong correlation of glucan and xylan yield for the HTPH system and followed the sugar yield patterns observed for application of HTPH to poplar [28]. However, the glucan or xylan yields without pretreatment did not show correlations (with $\mathrm{R}^{\wedge} 2$ less to 0.05 ) to those glucan and xylan yields for the pretreatment at $17.5 \mathrm{~min}$ and $35 \mathrm{~min}$ (Additional file 3: Figure S1). These results suggested that sugar yields from direct enzymatic hydrolysis of raw lignocellulosic biomass without pretreatment were not suitable predictors of sugar yields from enzymatic hydrolysis of pretreated biomass. However, the glucan yields for pretreatment at 17.5 min showed a very strong positive correlation (with $\mathrm{R}^{\wedge} 2$ of 0.757 ) to glucan yields for pretreatment at 35 min (Figure 2d). The correlation (with $\mathrm{R}^{\wedge} 2$ of 0.5907 ) between xylan yields for $17.5 \mathrm{~min}$ pretreatment and glucan yields for 35 min pretreatment (Figure 2f) was not as strong as that between glucan yields (Figure 2d) although positive correlations were found between xylan yields for $17.5 \mathrm{~min}$ pretreatment and glucan for $35 \mathrm{~min}$ pretreatment $\left(R^{\wedge} 2\right.$ of 0.5907 , Figure $\left.2 f\right)$, and between xylan yields for $17.5 \mathrm{~min}$ and for $35 \mathrm{~min}$ pretreatment $\left(\mathrm{R}^{\wedge} 2\right.$ of 0.5794 , Figure $\left.2 \mathrm{~g}\right)$.

Figures 3 and 4 show overall glucan yields (Stage 1+ Stage 2) versus original glucan content and overall xylan yields (Stage 1+ Stage 2) versus original xylan content for each Miscanthus sample to further investigate impacts of carbohydrate contents on glucan and xylan yields. The percent theoretical glucan yields based on original glucan content in raw Miscanthus ( $\mathrm{g} / \mathrm{g}$ original glucan) in Figure 3 ranged from $3.1 \%$ to $26.4 \%$ with averages of $13.3 \%$ for no pretreatment, from $36.8 \%$ to $71.3 \%$ with an average of $52.9 \%$ for 17.5 min pretreatment, and from $48.6 \%$ to $90.6 \%$ with an average of $69.3 \%$ for 35 min pretreatment. These HTPH results showed that theoretical glucan yields generally decreased as glucan content increased in raw Miscanthus. However, glucan mass yields (g/100 g dry weight Miscanthus), calculated as a percent of the total dry weight of raw Miscanthus tended to increase with glucan content of raw Miscanthus (in Additional file 3: Figure S1, glucan yields in column A7 for a 17.5 min pretreatment and in 


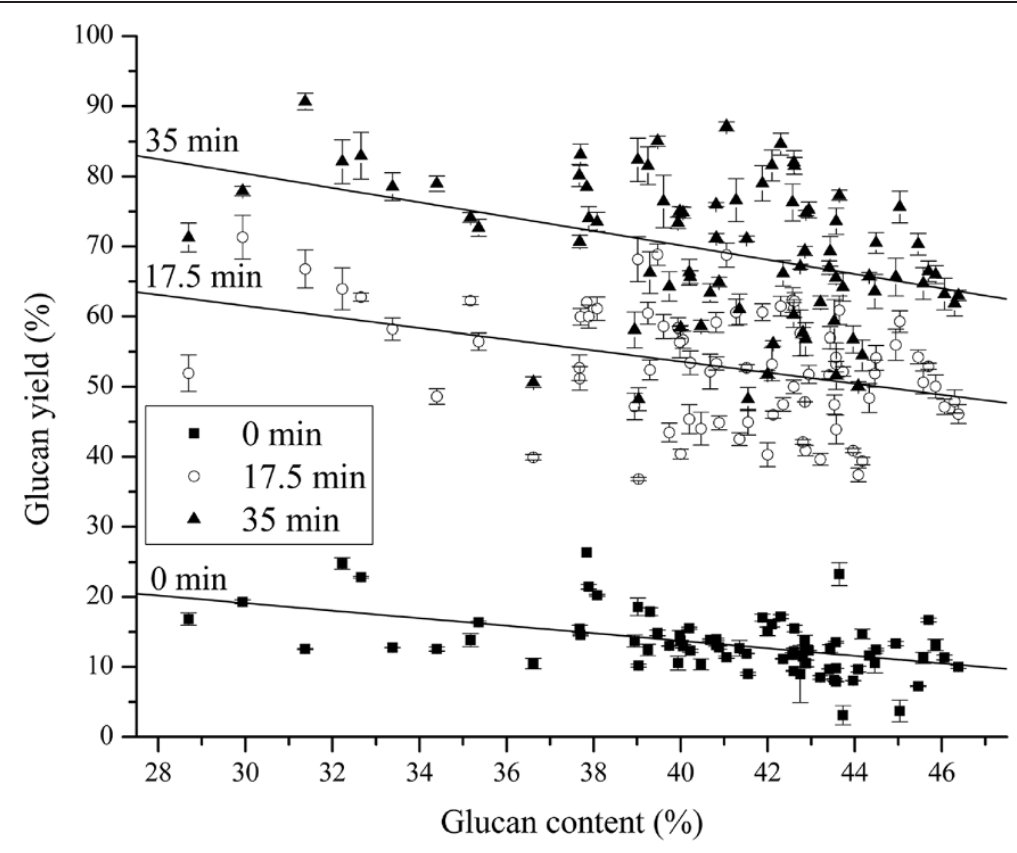

Figure 3 HTPH glucan yields 80 Miscanthus vs. glucan contents in raw Miscanthus at 3 different pretreatment times. HTPH glucan yields on basis of original glucan content in raw Miscanthus of 80 Miscanthus.

column A9 for a 35 min pretreatment). In other words, as glucan content in raw Miscanthus increased, it became more difficult to degrade glucan into glucose through pretreatment and enzymatic hydrolysis by $\mathrm{HTPH}$ under the experimental conditions applied even though the quantity of released glucose generally increased due to the greater amount. This negative effect became more significant when the pretreatment time was increased from 0 to $17.5 \mathrm{~min}$ and further to $35 \mathrm{~min}$. The mechanism can be a combination of various factors

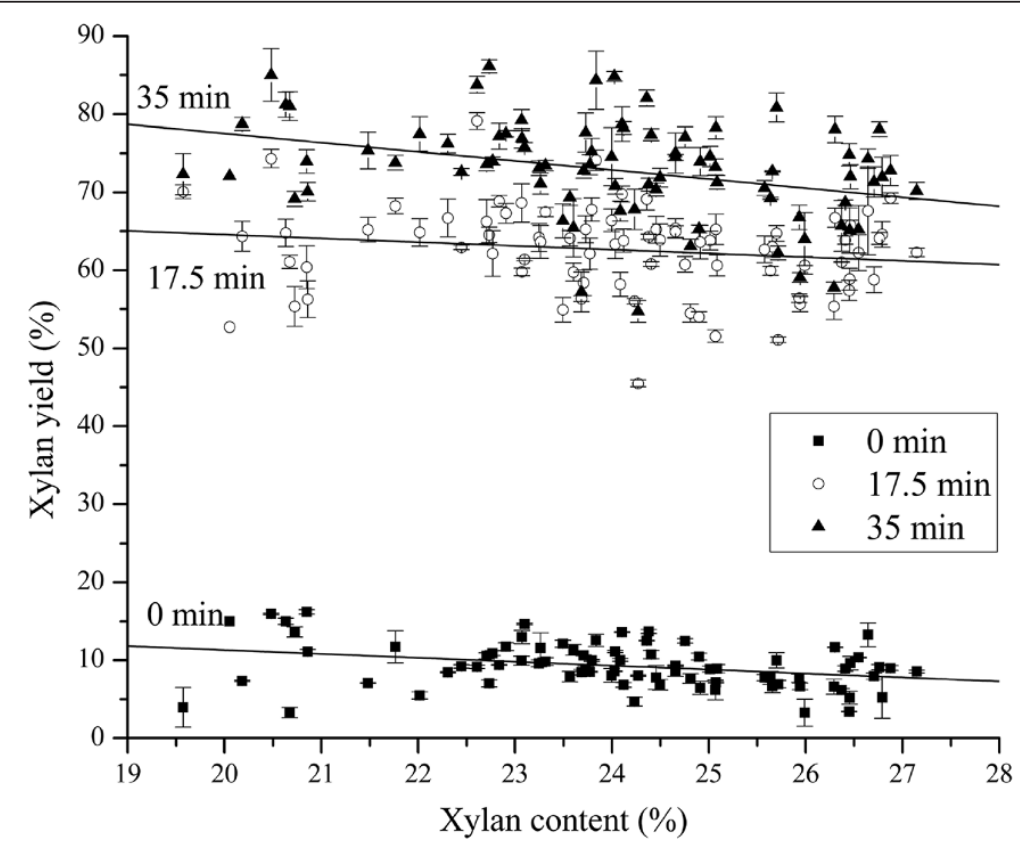

Figure 4 HTPH Xylan yields of 80 Miscanthus vs. glucan contents in raw Miscanthus at 3 different pretreatment times. HTPH xylan yields on basis of original glucan content in raw Miscanthus of 80 Miscanthus. 
and requires further investigation. A plausible explanation is inhibition of cellulases by higher concentrations of sugars released during HTPH from Miscanthus genotypes that contained higher amounts of glucan and/or xylan, especially when higher xylan yields were obtained as the pretreatment time was increased. It was reported recently that not only glucose but also xylose and particularly oligomeric xylan are strong inhibitors of cellulases [41,42]. Another possible mechanism would be greater amounts of cellulose presenting a more structured obstacle to enzyme action.

The percent of theoretical xylan yields ranged from $3.3 \%$ to $16.2 \%$ with an average of $9.3 \%$ for no pretreatment, from $45.5 \%$ to $79.1 \%$ with an average of $62.6 \%$ for 17.5 min pretreatment, and from $54.7 \%$ to $86.1 \%$ with an average of $72.9 \%$ for 35 min pretreatment (Figure 4). Xylan content in raw Miscanthus did not significantly affect xylan yields calculated on basis of the original xylan content of raw Miscanthus. Xylan content had more negative effects on theoretical xylan yields for unpretreated Miscanthus (0 min) than those for $17.5 \mathrm{~min}$ and $35 \mathrm{~min}$ pretreatments at $180^{\circ} \mathrm{C}$. With hydrothermal pretreatment at $180^{\circ} \mathrm{C}$ for $17.5 \mathrm{~min}$ and 35 min, HTPH results for 80 Miscanthus genotypes indicated that pretreatment conditions had a greater impact on xylan hydrolysis than xylan content in raw Miscanthus genotypes, in contrast to the findings for glucan yields in Figure 3.
The negative impacts of lignin on glucan and xylan mass yields (g/100 g raw Miscanthus) are shown in Additional file 3: Figure S1. In order to further investigate the impact of lignin content on overall glucan and xylan yields, the overall percent theoretical glucan and xylan yields based on original glucan and xylan contents are plotted versus lignin content of raw Miscanthus for 80 Miscanthus samples following hydrothermal pretreatment at $180^{\circ} \mathrm{C}$ for $0 \mathrm{~min}, 17.5 \mathrm{~min}$, and $35 \mathrm{~min}$ and subsequent enzymatic hydrolysis of the pretreated whole slurry in the HTPH system in Figure 5. The high scatter and significant deviation of glucan and xylan yields from a linear fit to lignin content show that lignin content was not a dominant factor in controlling hydrolysis through hydrothermal pretreatment followed by enzymatic hydrolysis of the whole slurry at a high enzyme loading of $75 \mathrm{mg}$ of cellulase plus $25 \mathrm{mg}$ of xylanase protein/g of total glucan plus xylan in the raw biomass.

Table 3 summarizes the 80 Miscanthus genotypes according to sample numbers provided by Mendel Biotechnology showing the highest and lowest sugar yields in terms of both mass yield ( $\mathrm{g}$ of $100 \mathrm{~g}$ dry weight raw Miscanthus) and percentage of theoretical yield (g sugar per gram of original glucan and xylan contents in raw Miscanthus) for no pretreatment and for a pretreatment time of $35 \mathrm{~min}$ as measured by HTPH. Overall, the genotypes with the highest or lowest sugar yields through

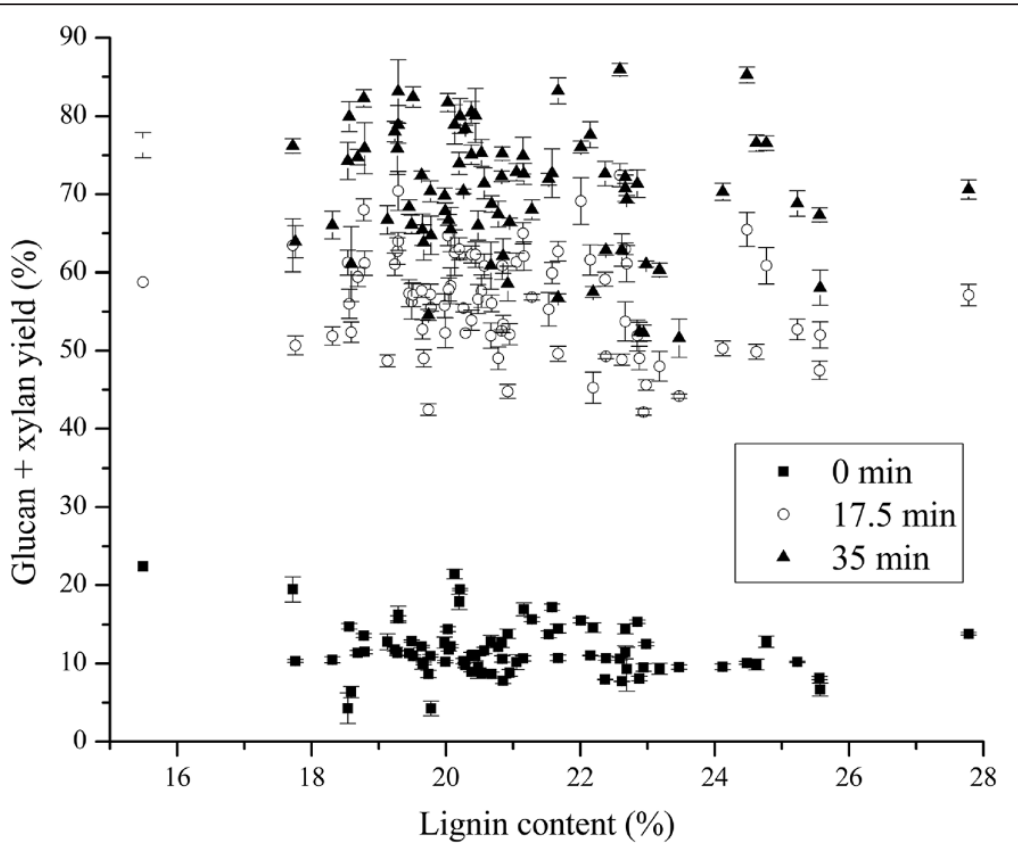

Figure 5 HTPH glucan and xylan yields of $\mathbf{8 0}$ Miscanthus samples vs. lignin contents in raw Miscanthus. HTPH glucan and xylan yields on basis of glucan + xylan content in raw Miscanthus of 80 Miscanthus samples. 
Table 3 Summary of HTPH results for Miscanthus genotypes displaying highest and lowest sugar yields

\begin{tabular}{|c|c|c|c|c|c|c|c|c|}
\hline \multirow[t]{2}{*}{ Description } & \multirow{2}{*}{$\begin{array}{l}\text { Pretreatment } \\
\text { time }(\mathrm{min}) * *\end{array}$} & \multirow{2}{*}{$\begin{array}{l}\text { Miscanthus } \\
\text { sample No. }\end{array}$} & \multicolumn{3}{|c|}{ Compositions $(\mathrm{g} / 100 \mathrm{~g} \mathrm{dw})$} & \multicolumn{3}{|c|}{ Sugar yield } \\
\hline & & & Glu & Xyl & Lig & Glu & Xyl & Glu + Xyl \\
\hline \multicolumn{9}{|l|}{ Highest yields } \\
\hline \multirow[t]{2}{*}{ Glu + xyl mass yield* } & 0 & 70 & 43.6 & 26.6 & 17.7 & 10.2 & 3.5 & 13.7 \\
\hline & 35 & 112 & 42.3 & 25.7 & 21.7 & 35.8 & 20.8 & 56.6 \\
\hline \multirow[t]{2}{*}{$\%$ of Glu $+x y l$ theoretical yield\# } & 0 & 4 & 37.8 & 20.1 & 15.5 & 26.4 & 15.0 & 22.4 \\
\hline & 35 & 229 & 41.1 & 22.6 & 22.6 & 87.1 & 85.4 & 86.5 \\
\hline \multirow[t]{2}{*}{ Glu mass yield } & 0 & 70 & 43.6 & 26.6 & 17.7 & 10.2 & 3.5 & 13.7 \\
\hline & 35 & 229 & 41.1 & 22.6 & 22.6 & 35.8 & 19.3 & 55.1 \\
\hline \multirow[t]{2}{*}{$\%$ of Glu theoretical yield } & 0 & 4 & 37.8 & 20.1 & 15.5 & 26.4 & 15.0 & 22.4 \\
\hline & 35 & 155 & 29.9 & 22.7 & 22.0 & 77.9 & 73.6 & 76.1 \\
\hline \multirow[t]{2}{*}{ Xyl mass yield } & 0 & 70 & 43.6 & 26.6 & 17.7 & 10.2 & 3.5 & 13.7 \\
\hline & 35 & 22 & 42.6 & 26.8 & 20.4 & 34.9 & 20.9 & 55.8 \\
\hline \multirow[t]{2}{*}{$\%$ of $\mathrm{Xyl}$ theoretical yield } & 0 & 152 & 32.2 & 20.8 & 20.1 & 24.8 & 16.2 & 21.4 \\
\hline & 35 & 191 & 37.7 & 22.7 & 19.5 & 80.1 & 86.1 & 82.4 \\
\hline \multicolumn{9}{|l|}{ Lowest yields } \\
\hline \multirow[t]{2}{*}{ Glu + xyl mass yield* } & 0 & 33 & 43.7 & 26.4 & 19.8 & 1.4 & 1.6 & 3.0 \\
\hline & 35 & 140 & 36.6 & 24.3 & 22.9 & 18.6 & 13.3 & 31.8 \\
\hline \multirow[t]{2}{*}{$\%$ of Glu $+x y l$ theoretical yield\# } & 0 & 33 & 43.7 & 26.4 & 19.8 & 3.1 & 6.2 & 4.2 \\
\hline & 35 & 141 & 39.0 & 23.7 & 23.5 & 48.2 & 57.2 & 51.6 \\
\hline \multirow[t]{2}{*}{ Glu mass yield } & 0 & 33 & 43.7 & 26.4 & 19.8 & 1.4 & 1.6 & 3.0 \\
\hline & 35 & 140 & 36.6 & 24.3 & 22.9 & 18.6 & 13.3 & 31.8 \\
\hline \multirow[t]{2}{*}{$\%$ of Glu theoretical yield } & 0 & 33 & 43.7 & 26.4 & 19.8 & 3.1 & 6.2 & 4.2 \\
\hline & 35 & 141 & 39.0 & 23.7 & 23.5 & 48.2 & 57.2 & 51.6 \\
\hline \multirow[t]{2}{*}{ Xyl mass yield } & 0 & 259 & 40.9 & 20.7 & 24.1 & 5.2 & 0.7 & 5.9 \\
\hline & 35 & 140 & 36.6 & 24.3 & 22.9 & 18.6 & 13.3 & 31.8 \\
\hline \multirow[t]{2}{*}{$\%$ of $X y l$ theoretical yield } & 0 & 259 & 40.9 & 20.7 & 24.1 & 12.8 & 3.3 & 9.6 \\
\hline & 35 & 140 & 36.6 & 24.3 & 22.9 & 50.7 & 54.7 & 52.3 \\
\hline
\end{tabular}

*mass yield calculated on basis of $100 \mathrm{~g}$ dry weight raw Miscanthus.

\#percent of theoretical yield was calculated on basis of the amount of original glucan or xylan contents in raw Miscanthus.

** The highest or lowest yields of HTPH for the pretreatment of 0 or $35 \mathrm{~min}$.

Glu-glucan, xyl-xylan, lig-lignin.

pretreatment were different from those with the highest or lowest sugar yields without pretreatment. The genotypes showing the highest mass yields were totally different from those with the highest theoretical yields, indicating that genotypes less resistant to HTPH did not necessarily release the highest quantity of sugars. The genotypes with the highest glucan plus xylan yields on the basis of both total mass and percentage of theoretical yields were similar to those with highest glucan yields because of the higher glucan content. The genotypes showing the highest glucan or glucan plus xylan yields without pretreatment contained lignin contents as low as 15.5\% and $17.7 \%$. However, the lignin contents of the genotypes realizing the highest glucan or glucan plus xylan yields with pretreatment ranged from $21.7 \%$ to $22.6 \%$, slightly higher than the $21.0 \%$ average lignin content of all 80 Miscanthus genotypes. 112 (M. sacchariflorus/M. sinensis) and 229 (Miscanthus lutarioriparius) showed similarly high glucan and xylan theoretical yields even though they had much different lignin contents. These results suggest that not only lignin content but also lignin composition impacted sugar yields, similar to results for a study of populus variants [28]. The lowest sugar yields were from two genotypes: 1) Sample 33 (M. sinensis) with a glucan plus xylan content of $70.1 \%$ had the lowest glucan and glucan plus xylan theoretical yields without pretreatment and 2) Sample 140 (M. sacchariflorus/ M. sinensis) with a glucan plus xylan content of $60.9 \%$ had the lowest glucan, xylan, and glucan plus xylan theoretical yields following pretreatment for $35 \mathrm{~min}$. Thus, 
these two samples displayed strong recalcitrance even though both glucan and xylan content were close to the average values. In addition, the same genotypes maintained the highest and lowest glucan or xylan theoretical yields as the pretreatment time was extended from 17.5 to $35 \mathrm{~min}$ at $180^{\circ} \mathrm{C}$, and these varieties were not the same as those showing the highest or lowest theoretical yields without pretreatment. This trend indicated that enzymatic hydrolysis of raw Miscanthus without pretreatment would not be effective for rapidly identifying varieties with high yield potential.

Overall, these 80 genotypes represented similarity of cellulosic biomass samples as well as diversity according to the range of the compositional data and fermentable sugars results. The compositional data for dry Miscanthus samples ranged from $27.6 \%$ to $48.8 \%$ glucan with an average of $40.8 \%$ and a standard deviation of $3.8 \%$, from $18.6 \%$ to $28.0 \%$ xylan with an average of $24.1 \%$ and a standard deviation of $2.0 \%$, and from $15.4 \%$ to $27.8 \%$ K-lignin with an average of $20.9 \%$ and a standard deviation of $2.0 \%$. The covariances of glucan and K-lignin, xylan and K-lignin, and glucan and xylan were found to be $-2.4,-0.6$, and 2.6 , respectively. The range of sugar yields also showed that many samples followed a general trend besides some significant outliners. The maximum glucan yields $(28.2 \mathrm{~g}$ glucan/100 g dry biomass and $35.8 \mathrm{~g}$ glucan/100 g dry biomass) were almost two times the minimum glucan yields (14.4 glucan/100 g dry biomass and $18.6 \mathrm{~g}$ glucan/100 g dry biomass) for $17.5 \mathrm{~min}$ and $35 \mathrm{~min}$ pretreatment, respectively. The difference between maximum and minimum xylan yields was smaller than that of glucan for both $17.5 \mathrm{~min}$ and $35 \mathrm{~min}$ pretreatment. The maximum glucan yields (28.2 g glucan/100 g dry biomass) for $17.5 \mathrm{~min}$ pretreatment were similar to the average glucan yield of 80 Miscanthus genotypes for $35 \mathrm{~min}$ pretreatment. The maximum xylan yields (18.6 g glucan/100 g dry biomass) for 17.5 min pretreatment were greater than the average xylan yield (17.5 g glucan/ $100 \mathrm{~g}$ dry biomass) of 80 Miscanthus genotypes for 35 min pretreatment. The covariances of glucan and xylan yields (\%) were found above 4.2, 14.0, and 17.7 for $0 \mathrm{~min}, 17.5 \mathrm{~min}$, and $35 \mathrm{~min}$ pretreatment followed by co-hydrolysis, respectively.

Among these 80 Miscanthus genotypes, M. sacchariflorus/ M. sinensis and Miscanthus lutarioriparius were the top two in terms of overall sugar theoretical yields of $83.2 \%$ and $86.5 \%$, respectively, after hydrothermal pretreatment for $35 \mathrm{~min}$ at $180^{\circ} \mathrm{C}$ followed by enzymatic hydrolysis. These results were equivalent to mass yields of $56.6 \mathrm{~g}$ glucan plus xylan/100 g dry Miscanthus and 55.1 g glucan plus xylan/ 100 g dry Miscanthus, respectively. Thus, the HTPH system enabled identification of several Miscanthus genotypes with potential for high sugar release. On this basis, $M$.
sacchariflorus/M. sinensis and Miscanthus lutarioriparius were selected for deconstruction in a flowthrough pretreatment to develop more detailed data on the time release patterns of glucan, xylan, and lignin that can help us understand what influences key performance differences. Other samples with greater than $60 \%$ overall sugar (glucan + xylan) theoretical yields are of potential interest for more detailed study.

This rapid selection method for fermentable sugar yields could be directly converted to ethanol yields according to the current sugar-to-ethanol conversion yield model/calculation $[38,43]$. This calculation could be applied to different Miscanthus genotypes and other biomass samples and further coupled with the corresponding biomass productivity model under different growing conditions to estimate ethanol yields for cultivation of certain lands with various biomass varieties $[9,13]$. Therefore, incorporating biomass productivity models with this HTPH screening method would enable better estimation of cellulosic ethanol production to assist in development of new energy crops and testing of cultivation conditions.

\section{Conclusions}

Compositional analysis of 80 Miscanthus genotypes showed glucan contents ranging from $28.7 \%$ to $46.4 \%$, xylan contents from $19.6 \%$ to $27.1 \%$, and total glucan plus xylan contents from $49.6 \%$ to $72.0 \%$ by dry weight. Thus, Miscanthus can have greater carbohydrate content than many other types of fast growing plants and hold promise for high ethanol yields. However, the large variability in composition among Miscanthus genotypes shows that appropriate genotypes must be chosen to realize this potential.

Application of our novel high throughput system $(\mathrm{HTPH})$ for hydrothermal pretreatment at $180^{\circ} \mathrm{C}$ followed by enzymatic hydrolysis of all 80 Miscanthus genotypes revealed that $M$. sacchariflorus/M. sinensis and Miscanthus lutarioriparius achieved the highest glucan plus xylan mass yields of $56.6 \mathrm{~g} / 100 \mathrm{~g}$ and $54.6 \mathrm{~g} / 100 \mathrm{~g}$, respectively, after pretreatment for 35 minutes. The total glucan plus xylan content in Miscanthus appeared to influence both mass and theoretical yields, while lignin and ash contents did not have a predictable influence on performance. Because the total glucan plus xylan yields by mild hydrothermal pretreatment and cohydrolysis of the 80 Miscanthus genotypes showed strong correlations to those at more severe (close to optimal) hydrothermal pretreatment and co-hydrolysis conditions, the mild pretreatment results could be used as a faster and lower cost preliminary indicator of promising cellulosic biomass that could realize high yields of fermentable sugar. 


\section{Methods \\ Materials}

Miscanthus $x$ giganteus $c v$. Illinois, a hybrid of Miscanthus sacchariflorus and Miscanthus sinensis [44] harvested in Illinois in the fall of 2007, was provided by Mendel Biotechnology, Inc. in Hayward, California. Miscanthus $x$ giganteus $c v$. Illinois materials, including leaves and stalks, were cut to shorter lengths, sealed in heavy duty zipped bags, and stored at $-18^{\circ} \mathrm{C}$ in a laboratory freezer. An appropriate amount of frozen Miscanthus was thawed at a temperature no higher than $25^{\circ}$ $\mathrm{C}$ and mixed completely. The material was then ground with a laboratory mill (model 4, Arthur H. Thomas Company, Philadelphia, PA) to pass between Sieve 20 and Sieve 60 and obtain particles over a size range of 250-850 $\mu \mathrm{m}$ for experiments and analysis. The most cultivated Miscanthus genotype in the United States, Miscanthus $x$ giganteus $c v$. Illinois, was used in our hydrothermal pretreatment study to find appropriate conditions to compare other genotypes. Single plants of another 80 Miscanthus genotypes (including Miscanthus sinensis, Miscanthus sacchariflorus, hybrids of these two, $M$. x giganteus, $M$. transmorrisonensis, $M$. tinctorius and $M$. lutarioriparius) were grown in one field plot at Klein-Wanzleben, Germany. Selected plants from collections or from crosses were added annually to the field plot, and biomass was harvested every year before the new shoots appeared in the spring. The plants did not receive fertilizer. Plants sampled for this study were between 2 and 17 years old, grown during the growing season 2007, and harvested by hand in April 2008. Miscanthus straw was shredded with a garden shredder and milled with a hammer mill. Plant origin, plant age, and monthly temperature and rainfall for the 2007 growing season are listed in Additional file 1: Table S1 and Additional file 2: Table S2. The 2007 growing season was characterized by higher than average temperature and rainfall. All of these samples were air dried and milled to less than $2 \mathrm{~mm}$ prior to shipping in sample bags to the University of California Riverside, where they were stored at $-18^{\circ} \mathrm{C}$ in a laboratory freezer.

\section{Miscanthus compositional analysis}

The moisture content of the prepared Miscanthus samples was determined with a laboratory moisture analyzer (Mettler Toledo, Model: HB43 Halogen Moisture Analyzer, Columbus, OH). Ash content was analyzed according to NREL Laboratory Analytical Procedures (Technical Report NREL/TP-510-42622) [45] as was extractives content (Technical Report NREL/TP-51042619) [46]. Klason lignin, glucan, and xylan contents were determined following the modified NREL Laboratory Analytical Procedure (Technical Report NREL/TP510-42618) [47]. This procedure employed a two-step acid hydrolysis: 1) about $300 \mathrm{mg}$ substrate was placed into a vial and hydrolyzed in $72 \%(\mathrm{w} / \mathrm{w})$ sulphuric acid at $30^{\circ} \mathrm{C}$ for 1 hour and 2) the substrate was further hydrolyzed in $4 \%(\mathrm{w} / \mathrm{w})$ sulphuric acid at $121^{\circ} \mathrm{C}$ for 1 hour. The sugars in the liquid were determined by HPLC.

\section{Batch hydrothermal pretreatment in tubular reactors}

Tubular reactors (Hastelloy C-276, O.D. 0.0127 m (0.5”) with wall thickness of $0.0008890 \mathrm{~m}(0.035$ "), length of $0.1524 \mathrm{~m}(6 ")$, and volume of $0.0143 \mathrm{~L}(14.3 \mathrm{ml})$ ) were employed for batch pretreatment of Miscanthus $x$ giganteus $c v$. Illinois to set baseline conditions. These reactors were heated in $4 \mathrm{~kW}$ fluidized sand baths (Model SBL2D, Technical Co., Princeton, NJ), with the internal temperature monitored with a $\mathrm{K}$ type thermocouple probe (Omega KQSS-316 G-12, Omega Engineering Co., Stamford, CT). The heat-up time to final reaction temperature was less than 200 seconds and included in the stated reaction time. The heat-up time was slightly longer for the higher temperature than for the lower temperature operation. Cooling down in a water bath to room temperature took about 40 seconds, which was not included in the reaction time.

Miscanthus $x$ giganteus $c v$. Illinois was presoaked in water overnight at a solids loading of $10 \mathrm{wt} \%$ for hydrothermal pretreatments at $180^{\circ} \mathrm{C}, 200^{\circ} \mathrm{C}$, and $220^{\circ} \mathrm{C}$. Following pretreatments, the slurry was separated into a liquid hydrolysate and pretreated solids by vacuum filtration using a $0.22 \mu \mathrm{m}$ glass fibber filter (09-804-110A, Fisher Science, Pittsburgh, PA). The pretreated solids were washed thoroughly with deionized water before compositional analysis and sequential enzymatic hydrolysis. Sugar yields in the liquid from just hydrothermal pretreatment were designated as Stage 1 sugar yields, and those from subsequent enzymatic hydrolysis of the pretreated solids were labelled as Stage 2 sugar yields.

\section{High throughput pretreatment and co-hydrolysis (HTPH)}

A novel high throughput pretreatment and enzymatic hydrolysis system (HTPH) was used for rapid screening of 80 Miscanthus varieties for sugar yields from coupled pretreatment and enzymatic hydrolysis [29]. The method was developed and proved equally effective as conventional batch reactors followed by washed solids hydrolysis [29]. The custom made well-plate consisted of 96 Hastelloy round cups (i.d $6.9 \mathrm{~mm}$ x $10.7 \mathrm{~mm}$ inside length) with reaction volumes of $300 \mu \mathrm{L}$ resting on an aluminium bottom plate, covered with a silicone gasket and stainless steel plate, and clamped tightly to contain the contents at pretreatment pressures and temperatures. This assembly was placed horizontally and lengthwise inside a custom made steam chamber made of readily available steam rated (to $1 \mathrm{MPa}$ steam pressure) 316 stainless steel $0.102 \mathrm{~m}$ (4") diameter fittings 
(McMaster, Santa Fe Springs, CA). A ball valve at one end allowed easy access for loading and unloading. Steam was generated by a high pressure steam boiler (FB-075-L, Fulton Companies, Pulaski, NY) and connected to the chamber along with cooling water. A reaction volume of $250 \mu \mathrm{L}$ with $2.6 \mathrm{mg}$ Miscanthus(i.e., 1\% w/w solids) and 247.4 $\mu \mathrm{L}$ water (8 channel pipetter, 30$300 \mu \mathrm{L}$, Eppendorf) was added to each well of the $\mathrm{HTPH}$ system. Miscanthus was incubated at room temperature for $4 \mathrm{~h}$ before pretreatment. Miscanthus samples were pretreated in the $\mathrm{HTPH}$ system at $180^{\circ} \mathrm{C}$ for $0,17.5$, and $35 \mathrm{~min}$. After the mixture of the liquid hydrolysate and pretreated solid was cooled down, the plate was opened, and an enzyme loading of $75 \mathrm{mg}$ of cellulase plus $25 \mathrm{mg}$ of xylanase protein/g of total glucan plus xylan for raw Miscanthus $x$ giganteus $c v$. Illinois was achieved by adding $20 \mu \mathrm{L}$ mixture of $0.625 \mathrm{M}$ citric acid buffer ( $\mathrm{pH}$ 4.7), $0.125 \mathrm{~g} / \mathrm{L}$ sodium azide, and enzymes (including $6.08 \mathrm{mg} / \mathrm{ml}$ Specyme CP cellulase and $2.03 \mathrm{mg} / \mathrm{ml}$ Multifect xylanase) to each well. Such high enzyme loading was applied to overcome possible inhibitory effects of compounds derived from pretreatment under different pretreatment conditions on sugar release. Xylanase was applied to hydrolyze xylooligomers in the liquid hydrolysate for co-hydrolysis, which was different from the enzymatic hydrolysis of pretreated solids in the batch reactor. Following addition of enzymes, sodium azide, and buffer, the plate was resealed and placed in an incubation shaker (Multitron Infors-HT, ATR Biotech, Laurel, MD) at $50^{\circ} \mathrm{C}, 150 \mathrm{rpm}$ for $72 \mathrm{~h}$. Samples were filtered by $2 \mathrm{~mL}$ centrifuge filter with pore size of $0.20 \mu \mathrm{m}(2 \mathrm{~mL}$ centrifuge filter (Catalogue no. 24137), Grace Davison, Deerfield, IL) immediately then frozen for sugar analysis.

\section{Sugar analysis}

Sugar monomers in the liquids from pretreatment and enzymatic hydrolysis were analyzed quantitatively by a Waters HPLC system (model 2695) equipped with a 2414 refractive detector and a Waters 2695 auto sampler using Waters Empower ${ }^{\mathrm{T \mu}} 2$ software (Waters Co.,
Milford, MA). Bio-Rad Aminex HPX-87 $\mathrm{H}$ and BioRad Aminex HPX-87P columns (Bio-Rad Laboratories, Hercules, CA) were employed for separation of sugars for quantification.

The concentrations of total xylan and glucan in the hydrolysate were determined by post-hydrolysis with $4 \%$ w/w sulphuric acid at $121^{\circ} \mathrm{C}$ for 1 hour according to NREL Laboratory Analytical Procedure (Technical Report NREL/TP-510-42623) [48]. Both glucan and xylan yields in Stage 1 were reported as the sum of monomer and oligomer yields.

\section{Enzymatic hydrolysis}

Washed solids from hydrothermal pretreatment of Miscanthus in the batch tubes were enzymatically hydrolyzed at $2 \%$ solids loadings with a $\mathrm{pH}$ value of 4.8 at $50^{\circ}$ $\mathrm{C}$ in duplicates by following modified NREL Laboratory Analytical Procedure (Technical Report NREL/TP-51042629) [49] using Spezyme CP (62 FPU/ml, protein content $116.0 \mathrm{mg} / \mathrm{ml}$, Genencor, Rochester, NY) and Novozymes 188 ( $\beta$-glucosidase, activity 665.0 CBU/ml, protein content $125.0 \mathrm{mg} / \mathrm{ml}$, Franklinton, NC). The ratio of cellulase filter paper activity to beta-glucosidase activity was FPU: $\mathrm{CBU}=1: 4$, and the total enzyme loading was $60 \mathrm{FPU} / \mathrm{g}$ (glucan + xylan) in the pretreated solids. Hydrolysis samples were collected at 72 hours, and sugar concentrations were determined for calculation of Stage 2 glucan and xylan yields.

\section{Calculations}

The $\log$ of the severity parameter $\left(\log R_{0}\right)$ for hydrothermal pretreatment was defined as a function of pretreatment temperature $\mathrm{T}\left({ }^{\circ} \mathrm{C}\right)$ and pretreatment time $\mathrm{t}(\mathrm{min})$, as [39]:

$$
\mathrm{R}_{0}=\mathrm{t} \cdot \exp \left(\frac{\mathrm{T}-100}{14.75}\right)
$$

Glucan and xylan yields and overall glucan and xylan yields for batch pretreatment and enzymatic hydrolysis were calculated as:

$$
\text { glucan yield }(\%)=\frac{\text { glucose conc. in the liquid hydrolysate }(g / L) * \text { total volume }(\mathrm{L}) * 0.9}{\text { initial Miscanthus amount }(g) * \text { original glucan content in the Miscanthus }(\%)} \times 100
$$

xylan yield $(\%)=\frac{\text { xylose conc.in the liquid hydrolysate }(g / L) * \text { total volume }(\mathrm{L}) * 0.8801}{\text { initial solid Miscanthus }(g) * \text { original xylan content in the Miscanthus }(\%)} \times 100$

$$
\begin{aligned}
& \text { glucan }+ \text { xylan yield }(\%) \\
& \qquad=\frac{\text { glucan yield } * \text { initial glucan in Miscanthus }(g)+\text { xylan yield } * \text { initial xylan in Miscanthus }(g)}{\text { initial glucan }+ \text { xylan in Miscanthus }(g)} \times 100
\end{aligned}
$$


These equations were applied to determine yields in Stage 1 (pretreatment) and Stage 2 (enzymatic hydrolysis). For Stage 1, sugar yields included both monomer and oligomers determined through post hydrolysis of the liquid hydrolysate. Sugar yields were calculated as percent of the theoretical maximum on the basis of original glucan and/or xylan content in raw Miscanthus unless otherwise specified. Overall glucan plus xylan yields were defined as the sum of glucan plus xylan yields from Stage 1 and Stage 2.

The calculations for the high throughput pretreatment and co-hydrolysis were based on the sugar amounts after co-hydrolysis following a previously published method [29]. Monomeric sugars in the liquid hydrolysate were measured after pretreatment and co-hydrolysis, and sugar yields were calculated by equations $2-4$.

\section{Additional files}

Additional file 1: Table S1. Information of the Miscanthus straw samples from Mendel Biotechnology, Inc. and composition data from UCR Summary of Miscanthus pretreatment data reported in the literature.

Additional file 2: Table S2. Weather data from airport Magdeburg, near Klein-Wanzleben.

Additional file 3: Figure S1. Normalized scatter matrix of 80 Miscanthus compositions, HTPH glucan and xylan mass yields $(\mathrm{g} / 100 \mathrm{~g}$ $\mathrm{dw}$ raw Miscanthus). HTPH glucan and xylan mass yields (g/100 $\mathrm{g}$ dw raw Miscanthus) from hydrothermal pretreatment at $180^{\circ} \mathrm{C}$ in $0,17.5 \mathrm{~min}$, and $35 \mathrm{~min}$.

\section{Abbreviations}

HTPH: High throughput pretreatment and hydrolysis; FPU: Filter paper unit; CBU: Cellobiase unit.

\section{Competing interests}

CEW is cofounder of Mascoma Corporation and chair of their Scientific Advisory Board. CEW is also member of the Scientific Advisory Board of Mendel Biotechnology, Inc. CEW is also founding Editor in Chief of this Journal BfB.

The other authors declare that they have no competing interests other than support of this research by Mendel Biotechnology.

\section{Authors' contributions}

TZ carried out this study under the supervision of BY and CEW. KJ provides logistic and background information for all Miscanthus samples. All the authors read and accepted this final manuscript.

\section{Acknowledgements}

We are grateful to Mendel Biotechnology, Inc., for funding this research and Drs. James Zhang and Karen Century for their advice. In addition, the High throughput Pretreatment and Hydrolysis ( $\mathrm{HTPH})$ system developed through the BioEnergy Science Center (BESC) and supported by the Office of Biological and Environmental Research in the DOE Office of Science was vital to this research. Thanks to Drs. Michael H. Studer and Jaclyn D. DeMartini for their assistance in the use of the HTPH system and Ms. Karen Xu for her assistance in statistical analyses. We also acknowledge the Center for Environmental Research and Technology (CE-CERT) of the Bourns College of Engineering for providing facilities used in this research and the Ford Motor Company for funding the Chair in Environmental Engineering that facilitates projects such as this one.

\section{Author details}

${ }^{1}$ Center for Environmental Research and Technology, Bourns College of Engineering, University of California, 1084 Columbia Avenue, Riverside, CA
92507, USA. ${ }^{2}$ Chemical and Environmental Engineering Department, Bourns College of Engineering, University of California, Riverside, CA 92521, USA. ${ }^{3}$ Mendel Biotechnology Inc., 3935 Point Eden Way, Hayward, CA 94545, USA. ${ }^{4}$ Center for Bioproducts and Bioenergy, Washington State University, 2710 University Drive, Richland, WA 99354, USA.

Received: 27 March 2012 Accepted: 20 June 2012

Published: 3 August 2012

\section{References}

1. Kerr RA: Bumpy road ahead for world's oil. Science 2005, 310:1106-1108.

2. Kerr RA, Service RF: What can replace cheap oil - and when. Science 2005, 309:101-101.

3. Kerr RA: Peak oil production may already be here. Science 2011, 331:1510-1511.

4. U.S. Department of Energy: In U.S. billion-ton update: biomass supply for a bioenergy and bioproducts industry. Edited by Perlack RD, Stokes BJ.: Oak Ridge National Laboratory, Oak Ridge, TN; 2011. ORNL/TM-2011/224, 227p.

5. Clifton-Brown J, Lewandowski I, Andersson B, Basch G, Christian D, Kjeldsen J, Jorgensen U, Mortensen J, Riche A, Schwarz K, et al: Performance of 15 Miscanthus genotypes at five sites in Europe. Agron J 2001, 93:1013-1019.

6. Kordsachia O, Seemann A, Patt R: Fast-growing Poplar and MiscanthusSinensis - future raw-materials for pulping in central-Europe. Biomass Bioenergy 1993, 5:137-143.

7. Lewandowski I, Clifton-Brown J, Scurlock J, Huisman W: Miscanthus: European experience with a novel energy crop. Biomass Bioenergy 2000, 19:209-227.

8. Pude R: New cultivation methods of Miscanthus in Europe. Berichte Uber Landwirtschaft 2003, 81:405-415.

9. Hastings A, Clifton-Brown J, Wattenbach M, Stampfl P, Mitchell CP, Smith P: Potential of Miscanthus grasses to provide energy and hence reduce greenhouse gas emissions. Agron Sustain Dev 2008, 28:465-472

10. Fike JH, Parrish DJ, Wolf DD, Balasko JA, Green JT, Rasnake M, Reynolds JH: Switchgrass production for the upper southeastern USA: Influence of cultivar and cutting frequency on biomass yields. Biomass Bioenergy 2006, 30:207-213

11. Heaton EA, Dohleman FG, Long SP: Meeting US biofuel goals with less land: the potential of Miscanthus. Glob Chang Biol 2008, 14:2000-2014.

12. Heaton EA, Dohleman FG, Miguez AF, Juvik JA, Lozovaya V, Widholm J, Zabotina OA, Mcisaac GF, David MB, Voigt TB, et al: Miscanthus: A Promising Biomass Crop. Adv Bot Res 2010, 56:75-137.

13. Maughan M, Bollero G, Lee DK, Darmody R, Bonos S, Cortese L, Murphy J, Gaussoin R, Sousek M, Williams D, et al: Miscanthus $\times$ giganteus productivity: the effects of management in different environments. GCB Bioenergy 2012, 4:253-265.

14. de Vrije T, de Haas G, Tan G, Keijsers E, Claassen P: Pretreatment of Miscanthus for hydrogen production by Thermotoga elfii. Int J Hydrog Energy 2002, 27:1381-1390.

15. Yoshida M, Liu Y, Uchida S, Kawarada K, Ukagami Y, Ichinose H, Kaneko S, Fukuda K: Effects of cellulose crystallinity, hemicellulose, and lignin on the enzymatic hydrolysis of Miscanthus sinensis to monosaccharides. Biosci Biotechnol Biochem 2008, 72:805-810.

16. Murnen H, Balan V, Chundawat S, Bals B, Sousa L, Dale B: Optimization of ammonia fiber expansion (AFEX) pretreatment and enzymatic hydrolysis of Miscanthus x giganteus to fermentable sugars. Biotechnol Prog 2007, 23:846-850.

17. Brosse N, Sannigrahi P, Ragauskas A: Pretreatment of Miscanthus $\mathrm{x}$ giganteus using the ethanol organosolv process for ethanol production. Ind Eng Chem Res 2009, 48:8328-8334.

18. Sorensen A, Teller P, Hilstrom T, Ahring B: Hydrolysis of Miscanthus for bioethanol production using dilute acid presoaking combined with wet explosion pre-treatment and enzymatic treatment. Bioresour Technol 2008, 99:6602-6607.

19. Wang B, Wang X, Feng H: Deconstructing recalcitrant Miscanthus with alkaline peroxide and electrolyzed water. Bioresour Technol 2010, 101:752-760.

20. Han K, Ko J, Yang S: Optimizing lignocellulosic feedstock for improved biofuel productivity and processing. Biofuels Bioprod Biorefining-Biofpr 2007, 1:135-146. 
21. Aden A, Foust T: Technoeconomic analysis of the dilute sulfuric acid and enzymatic hydrolysis process for the conversion of corn stover to ethanol. Cellulose 2009, 16:535-545.

22. Jackson L, Shadle G, Zhou R, Nakashima J, Chen F, Dixon R: Improving saccharification efficiency of Alfalfa stems through modification of the terminal stages of monolignol biosynthesis. Bioenergy Res 2008, 1:180-192.

23. Shen H, Fu C, Xiao X, Ray T, Tang Y, Wang Z, Chen F: Developmental Control of Lignification in Stems of Lowland Switchgrass Variety Alamo and the Effects on Saccharification Efficiency. Bioenergy Res 2009, 2:233-245.

24. Elander RT, Dale BE, Holtzapple M, Ladisch MR, Lee YY, Mitchinson C, Saddler JN, Wyman CE: Summary of findings from the Biomass Refining Consortium for Applied Fundamentals and Innovation (CAFI): corn stover pretreatment. Cellulose 2009, 16:649-659.

25. Perez J, Ballesteros I, Ballesteros M, Saez F, Negro M, Manzanares P: Optimizing Liquid Hot Water pretreatment conditions to enhance sugar recovery from wheat straw for fuel-ethanol production. Fuel 2008, 87:3640-3647

26. Suryawati L, Wilkins M, Bellmer D, Huhnke R, Maness N, Banat I: Effect of hydrothermolysis process conditions on pretreated switchgrass composition and ethanol yield by SSF with Kluyveromyces marxianus IMB4. Process Biochem 2009, 44:540-545.

27. Kim Y, Mosier N, Ladisch M: Enzymatic digestion of liquid hot water pretreated hybrid poplar. Biotechnol Prog 2009, 25:340-348.

28. Studer MH, DeMartini JD, Davis MF, Sykes RW, Davison B, Keller M, Tuskan GA, Wyman CE: Lignin content in natural Populus variants affects sugar release. Proc Natl Acad Sci U S A 2011, 108:6300-6305.

29. Studer MH, DeMartini JD, Brethauer S, McKenzie HL, Wyman CE: Engineering of a High-Throughput screening system to identify cellulosic biomass, pretreatments, and enzyme formulations that enhance sugar release. Biotechnol Bioeng 2010, 105:231-238.

30. DeMartini JD, Studer MH, Wyman CE: Small-scale and automatable HighThroughput Compositional analysis of biomass. Biotechnol Bioeng 2011, 108:306-312.

31. DeMartini JD, Wyman CE: Changes in composition and sugar release across the annual rings of Populus wood and implications on recalcitrance. Bioresour Technol 2011, 102:1352-1358.

32. Vandenbrink JP, Delgado MP, Frederick JR, Feltus FA: A sorghum diversity panel biofuel feedstock screen for genotypes with high hydrolysis yield potential. Ind Crops Prod 2010, 31:444-448.

33. Chundawat $S$, Balan V, Dale B: High-throughput microplate technique for enzymatic hydrolysis of lignocellulosic Biomass. Biotechnol Bioeng 2008, 99:1281-1294.

34. Bharadwaj R, Wong A, Knierim B, Singh S, Holmes BM, Auer M, Simmons BA, Adams PD, Singh AK: High-throughput enzymatic hydrolysis of lignocellulosic biomass via in-situ regeneration. Bioresource technol 2011 102:1329-1337.

35. Gao DH, Chundawat SPS, Krishnan C, Balan V, Dale BE: Mixture optimization of six core glycosyl hydrolases for maximizing saccharification of ammonia fiber expansion (AFEX) pretreated corn stover. Bioresour Technol 2010, 101:2770-2781.

36. Gao DH, Chundawat SPS, Uppugundla N, Balan V, Dale BE: Binding Characteristics of Trichoderma reesei Cellulases on Untreated, Ammonia Fiber Expansion (AFEX), and Dilute-Acid Pretreated Lignocellulosic Biomass. Biotechnol Bioeng 2011, 108:1788-1800.

37. Selig MJ, Tucker MP, Law C, Doeppke C, Himmel ME, Decker SR: High throughput determination of glucan and xylan fractions in lignocelluloses. Biotechnol Lett 2011, 33:961-967.

38. DOE Theoretical ethanol yield calculator. http://www1.eere.energy.gov/ biomass/ethanol_yield_calculator.html.

39. Overend RP, Chornet E: Fractionation of lignocellulosics by steamaqueous pretreatments. Phil Trans R Soc Lond 1987, A321:523-536.

40. Lloyd T, Wyman C: Combined sugar yields for dilute sulfuric acid pretreatment of corn stover followed by enzymatic hydrolysis of the remaining solids. Bioresour Technol 2005, 96:1967-1977.

41. Qing Q, Yang B, Wyman CE: Xylooligomers are strong inhibitors of cellulose hydrolysis by enzymes. Bioresour Technol 2010, 101:9624-9630.

42. Kumar R, Wyman CE: Effect of xylanase supplementation of cellulase on digestion of corn stover solids prepared by leading pretreatment technologies. Bioresour Technol 2009, 100:4203-4213.
43. Humbird RD D, Tao L, Kinchin C, Hsu D, Aden A, Schoen JL P, Olthof B, Worley $M$, Sexton D, Dudgeon D: Process Design and Economics for Biochemical Conversion of Lignocellulosic Biomass to Ethanol Dilute-Acid Pretreatment and Enzymatic Hydrolysis of Corn Stover:: National Renewable Energy Laboratory, Golden, CO; 2011. NREL/TP-5100-47764.

44. Hodkinson TR, Chase MW, Takahashi C, Leitch IJ, Bennett MD, Renvoize SA: The use of DNA sequencing (ITS and trnL-F), AFLP, and fluorescent in situ hybridization to study allopolyploid Miscanthus (Poaceae). Am J Bot 2002, 89:279-286.

45. Sluiter A, Ruiz BH, Scarlata CR, Sluiter J, Templeton D: Determination of ash in biomass laboratory analytical procedure. Golden, CO: National Renewable Energy Laboratory Analytical Procedure; 2005.

46. Sluiter A, Ruiz BH, Scarlata CR, Sluiter J, Templeton D: Determination of extractives in biomass laboratory analytical procedure. Golden, CO: National Renewable Energy Laboratory Analytical Procedure; 2005.

47. Sluiter A, Ruiz BH, Scarlata CR, Sluiter J, Templeton D, Crocker AD: Determination of structural carbohydrates and lignin in biomass laboratory analytical procedure. Golden, CO: National Renewable Energy Laboratory Analytical Procedure; 2008.

48. Sluiter A, Ruiz BH, Scarlata CR, Sluiter J, Templeton D: Determination of sugars, byproducts, and degradation products in liquid fraction process samples laboratory analytical procedure. Golden, CO: National Renewable Energy Laboratory Analytical Procedure; 2006.

49. Selig M, Weiss N, Ji Y: Enzymatic saccharification of lignocellulosic biomass laboratory analytical procedure. Golden, CO: National Renewable Energy Laboratory Analytical Procedure; 2006.

doi:10.1186/1754-6834-5-56

Cite this article as: Zhang et al:: Rapid selection and identification of Miscanthus genotypes with enhanced glucan and xylan yields from hydrothermal pretreatment followed by enzymatic hydrolysis. Biotechnology for Biofuels 2012 5:56.

\section{Submit your next manuscript to BioMed Central and take full advantage of:}

- Convenient online submission

- Thorough peer review

- No space constraints or color figure charges

- Immediate publication on acceptance

- Inclusion in PubMed, CAS, Scopus and Google Scholar

- Research which is freely available for redistribution 